\title{
Comparison of Campylobacter spp. and flock health indicators of broilers in Iceland
}

\author{
Michal Seman ${ }^{1,2, A-D \oplus}$, Gabriela Gregova ${ }^{1, A, C-D, F} \oplus$, Peter Korim ${ }^{1, A, D-F \oplus}$ \\ 1 University of Veterinary Medicine and Pharmacy, Košice, Slovak Republic \\ ${ }^{2}$ Icelandic Food and Veterinary Authority (MAST), Iceland \\ A - Research concept and design, B - Collection and/or assembly of data, C - Data analysis and interpretation, \\ $D$ - Writing the article, $E$ - Critical revision of the article, F-Final approval of article
}

Seman M, Gregova G, Korim P. Comparison of Campylobacter spp. and flock health indicators of broilers in Iceland. Ann Agric Environ Med. 2020; 27(4): 579-584. doi: 10.26444/aaem/127181

\begin{abstract}
Introduction. The safety of poultry meat products and contamination with microorganisms is based on appropriate reduction of the presence of pathogens during poultry rearing and is closely related to the level of rearing hygiene, including the type of housing, stocking density, microclimate, sanitation and ventilation.

Objective. The aim of the study is to evaluate the prevalence of Campylobacter-positive samples in Iceland during 20162018 , and to compare the potential influence of individual parameters of welfare on the prevalence of Campylobacter spp. Materials and method. Positivity of excrement and caecum samples for Campylobacter spp. was determined according to ISO 10272-1: 2006 and 2017. Data of welfare indicators were collected during the rearing period and in the slaughterhouse. Results. Considerable seasonality was observed in the prevalence of Campylobacter spp. The prevalence of campylobacteriosis on the investigated broiler farms was significantly higher $(p<0.05)$ during the summer. Comparison of welfare parameters on Campylobacter-positive and Campylobacter-negative farms failed to indicate a significantly higher level of observed welfare indicators in birds from Campylobacter-positive farms ( $>>0.05)$. In comparing small, medium and big farms, a significantly higher occurrence was observed $(p<0.05)$ of the FPD score over 40 , stocking density, and the average slaughter weight, and percentage of mortality over $2 \%$ in small farms.

Conclusions. Intensive management and the environment affect the welfare of poultry and its resistance to infections (Campylobacteriosis) and thus increase the health risk. Checking the welfare parameters in a slaughter house provides delayed improvement of the environment on farms, but it can also lead to changes in the following production cycles (decreasing of stocking density).
\end{abstract}

\section{Key words}

Campylobacter spp., welfare indicator, broiler chicken

\section{INTRODUCTION}

Generally, the fattening of poultry and production of broilers focuses on high productivity and effectiveness which results in poor welfare of broiler chickens. Today, the high rate of growth of commercial broilers allows the farmers to produce birds of $1.5 \mathrm{~kg}$ body weight within 30 days, compared to 120 days needed in the 1950s [1]. This fac, together with intensive management that does not provide the chickens with a suitable and stimulating environment, negatively affects their welfare and results in higher mortality, locomotion problems, heart failure, sudden death syndrome, ascites, contact dermatitis and behavioural problems, such as cannibalism [2].

The safety of poultry meat products concerning the presence of Campylobacter spp. and other microorganisms must be based particularly on preventive measures and appropriate reduction of the occurrence of pathogens in the rearing environment [3]. Microbial contamination of poultry carcasses is closely related to the level of breeding hygiene, including the type of housing, stocking density, microclimate, sanitation and ventilation of poultry housings.

Campylobacter spp. is the main agent causing bacterial gastroenteritis in humans worldwide, and the number of reported cases in the EU increases annually. It is one of the

Address for correspondence: Gabriela Gregova, University of Veterinary Medicine and Pharmacy, Komenskeho, 04181 Košice, Slovak Republic

E-mail: gabriela.gregova@uvlf.sk

Received: 17.12.2019; accepted: 02.09.2020; first published: 29.09.2020 most frequent causative agents of bacterial diarrhoea that accompanies especially the consumption of food of animal origin that was not subjected to adequate thermal treatment, particularly poultry meat and products from this meat. An insufficient level of hygiene in the processing of poultry in a slaughterhouse may result in contamination of the meat with Campylobacter spp. that occurs in animal excrements [4].

The causative agents of campylobacteriosis include the bacteria Campylobacter coli and Campylobacter jejuni. Frequently, typical Campylobacter spp. infection cannot be distinguished from infections caused by other enteric pathogens, such as Salmonella spp., Shigella spp. and E. coli. The incubation period is two to five days and the characteristic signs of this acute gastrointestinal disease include moderate to serious watery or bloody diarrhoea, fever, nausea, apathy and bellyache. The patients usually recover within one week, but in children and the elderly this infection may be more serious and may lead to consequences such as Guillain-Barre syndrome, reactive arthritis, myocarditis, irritable bowel syndrome and inflammatory disease of gut, and may result in hospitalisation [5].

Campylobacter spp. occur in the excrements of the majority of animals, although birds are the most frequent hosts, probably due to their higher body temperature $\left(42^{\circ} \mathrm{C}\right)$, which is ideal for moderately thermophilic Campylobacter species such as C. jejuni and C. coli [6].

Colonization of the chicken flock occurs after exposure to bacteria from their environment, and the presence of 
Campylobacter spp. in the gut may be detected already after several hours [7]. The minimum oral dose required for colonization of chickens can be as low as $35 \mathrm{CFU}$ [8], depending on breed and age of the chickens, the microorganism strain and route of infection [9]. Biosecurity measures on poultry farms aim to protect the birds against the development of infectious diseases by preventing the entry and spread of disease agents, including Campylobacter spp. As far as broiler flocks are concerned, the main risk of infection caused by Campylobacter spp. is the horizontal transfer from environmental sources. Campylobacter spp. are frequently found in puddles and stagnant water where they are protected against drying out [7]. The conventional, well managed, closed housing with limited access to pathogens, is considered biologically safe [10].

The risk factors, such as human activities, insects, wild birds and rodents, may also serve as vectors of campylobacteriosis on poultry farms. Immediately after the introduction of Campylobacter spp. into the broiler flock, the spread is extremely rapid and in the majority of cases all birds may be colonized within several days. Common feeders and drinkers together with the normal coprophagous activity of broilers facilitate the spreading of campylobacteriosis among the birds [11].

It was reported that the risk factors supporting colonization of broiler flocks with Campylobacter spp. include the size of the flock and a large number of rearing units on the farm. An increased number of birds is associated with higher demands on sources, such as personnel, manipulation, feed, and others. Large flocks may be transported to slaughterhouses in several shipments, sometimes distributed over several days, which increases the number of sources of Campylobacter spp. colonization for the birds remaining on the farm. One infected housing is a sufficient source for infecting all other birds on the farm with Campylobacter spp. [12].

Animals exposed to poor living conditions on intensive farms are more susceptible to infections. Stress is an important factor that reduces the ability of birds to resist effectively to bacterial infections. Acute stress during the catching and transportation of birds is associated with increased elimination of excrements and the presence of Campylobacter spp. [13].

Intensive management and environment affect the welfare of poultry and its resistance to infections (campylobacteriosis), and thus also increase the risk to public health related to zoonoses. A higher prevalence of Campylobacter spp. was reported among free-range poultry systems that allow access of birds to the outer environment. Increased demands of consumers on poultry meat produced in systems with a higher level of welfare raises the question of whether such welfareoriented keeping of animals is compatible with the safety of food of animal origin and the protection of public health [14].

According to EFSA [4], analysis of the content of broiler caecum conducted in the EU showed a $71 \%$ prevalence of Campylobacter spp. Previous studies indicated a lower prevalence of infection in broiler flocks in Finland, which is most likely related to the practice resulting in higher biosecurity and colder weather and decreased presence of vectors (flies). Also, broiler poultry is slaughtered there at a lower age (33-35 days, and partial decrease of the density of stacking during production cycle is not practiced. A lower number of halls on individual farms and newer rearing equipment may also play a role [15].

\section{OBJECTIVE}

The aim of the study is to evaluate the prevalence of Campylobacter-positive samples in two slaughterhouses in Iceland in 2016-2018, and to compare the potential influence of individual parameters of the welfare on the prevalence of Campylobacter spp.

\section{MATERIALS AND METHOD}

Welfare parameters and prevalence of Campylobacter spp. were determined in two poultry slaughterhouses in the southwestern region of Iceland, the so-called large Reykjavik area.

During 2016-2018, 857 flocks were evaluated, of which 41 were Campylobacter-positive. These results were compared with the measured welfare parameters.

The poultry slaughtered in Matfugl originates from 7 farms, and broilers and turkeys processed in Ísfugl from 9 farms where 4 of them are not owned by the slaughterhouse. The distance of farms from the slaughterhouses differs much - 30 - cca $100 \mathrm{~km}$ (only in one case the distance of the farm from slaughterhouse was $398 \mathrm{~km}$ ). The evaluation was carried out during the rearing period, and the slaughter process and evaluated flocks were of the same hybrid (Ros 308) reared on farms using the same production systems, negative pressure ventilation system, but differing in standards of life conditions, size of the halls and stocking density.

The welfare parameters evaluated during the rearing period and in the slaughterhouses included the following: $\%$ mortality, age of birds, \% dead on arrival (DOA), weight of slaughtered birds, stocking density in the rearing halls $\left(\mathrm{kg} / \mathrm{m}^{2}\right)$, total score of footpad dermatitis (FPD), cleanliness of bodies, \% of trauma and total rejection of birds in \%. DOA refers to the percentage of the flock that died in transit between the growing facility and the slaughterhouse. The percentage of trauma is the sum of all injuries: occurrence of leg and wing fractures, open fractures, injuries to the body (or wounded birds), and haematomas.

Total rejection of birds is the number of carcasses declared unfit for human consumption during the post-mortem inspection after evisceration. The most common in both slaughterhouses were the following conditions: pericarditis, perihepatitis, ascites, tumours, salpingitis and contamination.

For evaluation of FPD (footpad dermatitis), 100 broilers from each group were checked according a 0-200 scoring system (score $0-40=$ no deviation; score $41-80=$ mean deviation, and score 81-200 mean = severe deviation) [16]. The feet are evaluated on a tree scale ( 0 scale - no remarks; 1 scale - minor injury, small tissue damage; 2 scale - severe injury, large tissue damage).

Total score $\mathbf{F P D}=($ No. of feet in scale $0 \times 0)+$ $+($ No. of feet in scale $1 \times 0,5)+($ No. of feet in scale $2 \times 2)$

Accordingly, the FPD total score could be reduced by the stocking density on the farm [16].

Plumage cleanliness was assessed at slaughter on the breast of the birds with scores: $0=$ completely clean feathers, $1=$ slightly dirty, and $2=$ moderately dirty on the central part of abdomen, and 3 = extensive dirt on abdomen and wings [17].

Campylobacter spp. in the samples of excrements were determined according to EN ISO 'Microbiology of food 
and animal feed - Horizontal method for detection and determination of the counts of Campylobacter spp.' Part 1: Method of detection EN ISO 10272-1:2006 [18] and EN ISO 10272-1: 2017 [19, and Part 2: Colony-count technique (Technical Specification) EN ISO 10272-2:2006 [20], EN ISO 10272-2:2017 [21], or according to NMKL, Method No. 119, 2007 ( $3^{\text {rd }}$ edn.) [22].

From each flock (one building), a sample of excrement was sent for Campylobacter spp. detection. 10 samples of excrement were collected from each building a maximum of 5 days before slaughtering; at least 10 grams was a complete summary sample. 10 samples of caeca were taken from each flock during slaughtering [18]. Campylobacter-positive flockis the whole amount of birds from one building where positive results were detected from defined samples of excrement taken at the farm or positive results were detected in the slaughterhouse.

Usually 5 days before slaughtering, the average outside temperature was measured during the collecting of the samples (excrements) at the farm. The data were used for comparison of the influence of temperature on the prevalence of Campylobacter-positive cases, and for evaluation of the seasonality of campylobacteriosisoin broiler farms in Iceland. 1. Obtained results were processed statistically.

2. For statistical analysis, the flocks were divided according to the size of available floor area to the three categories: small flocks (up to $350 \mathrm{~m}^{2}$ ), medium flocks (up to $650 \mathrm{~m}^{2}$ ) and big flocks (over $650 \mathrm{~m}^{2}$ ).

3. Prevalence of Campylobacter spp. was evaluated, according to increasing temperature, seasonal changes, and welfare parameters using the chi-square test. For variables associated significantly with Campylobacter colonization (comparing Campylobacter-positive flocks to Campylobacter-negative flocks), were analyzed using Fisher's exact tests. For all tests, values of $\mathrm{p}<0.05$ were considered statistically significant.

\section{RESULTS}

By examination of the samples of excrements from broiler farms and caecum samples from slaughterhouses in Iceland during 2001-2018 a decrease in Campylobacter-positive flocks. was detected. Infected broiler chickes from the investigated farms decreased 10 -fold during this period, from the original prevalence of more than $20 \%$ in 2001 to $2.1 \%$ in 2018 .

Comparison of the prevalence of Campylobacter spp. In the individual years (2001-2018) and seasons indicated significant seasonality of this disease. The peak was observed in summer months (June - September) and the lowest prevalence was recorded during the cold season (December - March). In March, no Campylobacter-positive samples were found throughout the investigated period.

Comparison of Campylobacter-positive cases in different temperature intervals during ars 2016-2018 indicated significant differences related to the external environmental temperature $(\mathrm{Chi} 2=30.58 ; p<0.001)$. With the increasing temperature, the number of Campylobacter-positive samples also increased (Fig. 1).

In the temperature range from $-3^{\circ} \mathrm{C}-0.9^{\circ} \mathrm{C}$, the prevalence of positive samples reached $0 \%$, in range $1^{\circ} \mathrm{C}-4.9^{\circ} \mathrm{C}$ only $1.07 \%$, but in the temperature interval $5-8.9^{\circ} \mathrm{C}$ the prevalence was $5.77 \%$ Campylobacter-positive cases, and in the interval $9-13^{\circ} \mathrm{C}$ the prevalence higher $-10.12 \%$.

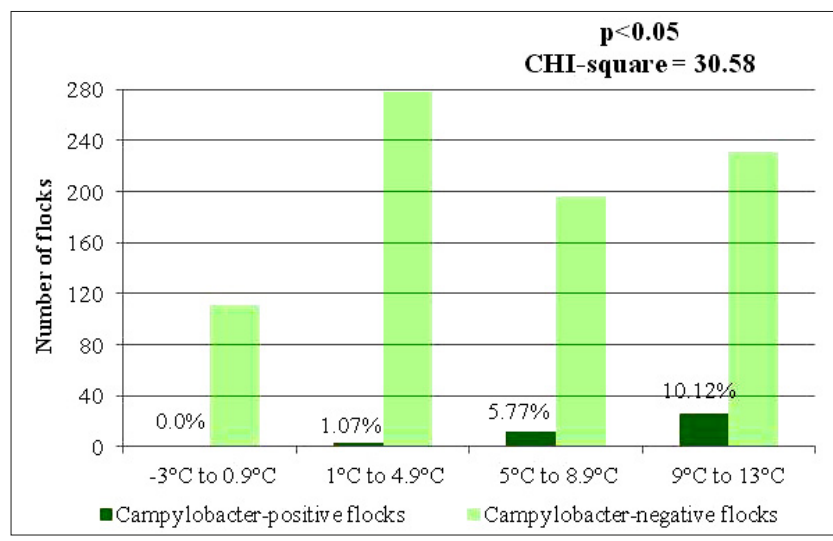

Figure 1. Prevalence of Campylobacter-positive samples originating from broilers depending on increasing external environmental temperature (average day temperature), 2016-2018

Table 1. Comparison of individual parameters of welfare of broilers on Campylobacter-positive and Campylobacter-negative flocks in Iceland, 2016-2018

\begin{tabular}{lccc}
\hline & $\begin{array}{c}\text { Flocks positive for } \\
\text { Campylobacter spp. }\end{array}$ & $\begin{array}{c}\text { Flocks negative for } \\
\text { Campylobacter spp. }\end{array}$ & $p<0.05$ \\
\hline Mortality $>2 \%$ & $22(53.7 \%)$ & $330(40.4 \%)$ & 0.105 \\
\hline Mortality $<2 \%$ & 19 & 486 & 0.052 \\
\hline DOA $>1 \%$ & $8(19.5 \%)$ & $76(9.3 \%)$ & 0.051 \\
\hline DOA $<1 \%$ & 33 & $344(42.2 \%)$ & \\
\hline$\%$ of trauma $>2 \%$ & $24(58.5 \%)$ & 472 & 0.153 \\
\hline$\%$ of trauma $<2 \%$ & 17 & $234(28.7 \%)$ & \\
\hline$\%$ of total rejected $(>0.5 \%)$ & $7(17.1 \%)$ & 582 & \\
\hline$\%$ of total rejected $(<0.5 \%)$ & 34 & $28(3.4 \%)$ & 0.650 \\
\hline FPD score over 40 & $2(4.9 \%)$ & 788 & \\
\hline FPD score under 40 & 39 & & \\
\hline
\end{tabular}

Almost all welfare indicators were higher in Campylobacterpositive flocks, but there was no significant difference in these factors in Campylobacter-positive flocks and Campylobacternegative flocks. The occurrence of mortality over $2 \%$ was $53.7 \%$ vs. $40.4 \%$ in Campylobacter-negative flocks (mortality $53.7 \%$ vs. $40.4 \%$, $\%$ of DOA $19.5 \%$ vs. $9.3 \%$, \%of trauma $58.5 \%$ vs. $42.2 \%$, FPD score over $40-4.9 \%$ vs. $3.4 \%$ ) (Tab. 1). Comparison of flocks with and without occurrence of Campylobacter spp. showed no significant differences in the mortality exceeding the $2 \%$ limit $(p=0.105), \%$ of total rejection of birds exceeding $0.5 \%(p=0.153)$ and $\%$ of trauma $(\mathrm{p}=0.051)$.

Footpad dermatitis (FPD) is an important indicator of poultry welfare. Comparison of the results of FPD score higher than 40 between Campylobacter-positive and Campylobacter-negative flocks showed no significant increase in this parameter related to positivity $(\mathrm{p}>0.05)$ (Tab. 1). 


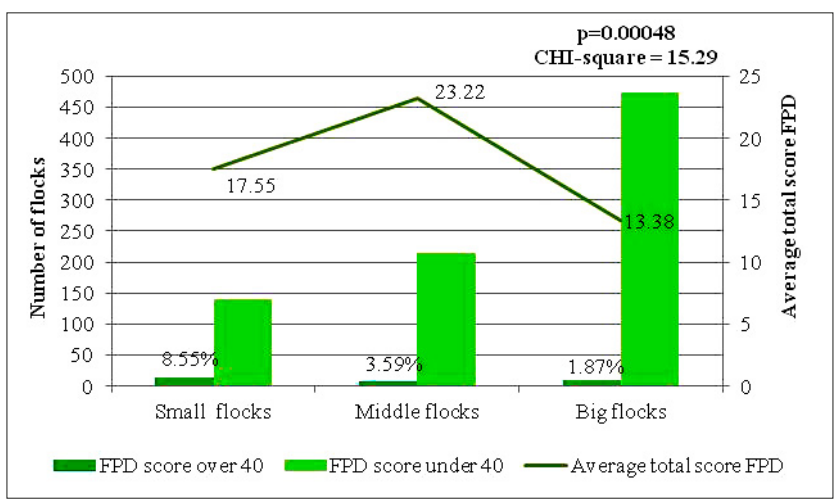

Figure 2. Prevalence of FPD in small, medium and big flocks in Iceland, 2016-2018

By comparison of small, medium and big flocks, significant differences were observed in welfare indicators. The results of the FPD score over 40 show a significant difference $(\mathrm{p}=0.00048)$. In small flocks, the total FPD score of 40 was exceeded in $8.55 \%$, and in medium flocks, in $3.59 \%$; in big flocks it was exceeded only in $1.87 \%$. However, the total score of more than 80 was exceeded only a few times (small flocks - twice, middle flocks - once, big flocks - twice). The average value of the FPD score ranged from 13.38-23.22 in the studied flocks (Fig. 2).

Table 2. Comparison of individual parameters of welfare in small, middle and big flocks in Iceland during the years 2016-2018

\begin{tabular}{|c|c|c|c|c|c|}
\hline & $\begin{array}{l}\text { Small } \\
\text { flocks }\end{array}$ & $\begin{array}{l}\text { Medium } \\
\text { flocks }\end{array}$ & Big flocks & Chi2 & $p<0.05$ \\
\hline $\begin{array}{l}\text { Campylobacter } \\
\text { positive flocks }\end{array}$ & $5(3.3 \%)$ & $7(3.1 \%)$ & $29(6.0 \%)$ & 3.67 & 0.159 \\
\hline $\begin{array}{l}\text { Campylobacter } \\
\text { negative flocks }\end{array}$ & 147 & 216 & 453 & & \\
\hline Mortality (>2\%) & 70 (46.1\%) & $106(47.5 \%)$ & 176 (36.5\%) & 10.33 & 0.0085 \\
\hline Mortality (<2\%) & 82 & 117 & 306 & & \\
\hline $\mathrm{DOA}>1 \%$ & $7(4.6 \%)$ & $6(2.7 \%)$ & 71 (14.7\%) & 30.64 & $<0.00001$ \\
\hline $\mathrm{DOA}<1 \%$ & 145 & 217 & 411 & & \\
\hline $\begin{array}{l}\text { Cleanliness of body } \\
(\text { level }>1)\end{array}$ & 77 (50.7\%) & 90 (40.4\%) & $194(40.2 \%)$ & 5.52 & 0.063 \\
\hline $\begin{array}{l}\text { Cleanliness of body } \\
\text { (level }<1)\end{array}$ & 75 & 133 & 288 & & \\
\hline $\begin{array}{l}\text { Average slaughter } \\
\text { weight }(>1.8 \mathrm{~kg})\end{array}$ & $26(17.1 \%)$ & $14(6.3 \%)$ & $9(1.9 \%)$ & 49.95 & $<0.00001$ \\
\hline $\begin{array}{l}\text { Average slaughter } \\
\text { weight }(<1.8 \mathrm{~kg})\end{array}$ & 126 & 209 & 473 & & \\
\hline $\begin{array}{l}\text { Stocking density } \\
\left(>39 \mathrm{~kg} / \mathrm{m}^{2}\right)\end{array}$ & 45 (29.6\%) & $33(14.8 \%)$ & $11(2.3 \%)$ & 99.00 & $<0.00001$ \\
\hline $\begin{array}{l}\text { Stocking density } \\
\left(<39 \mathrm{~kg} / \mathrm{m}^{2}\right)\end{array}$ & 107 & 190 & 471 & & \\
\hline Trauma (>2\%) & $60(39.5 \%)$ & $103(46.2 \%)$ & 205 (42.5\%) & 1.738 & 0.419 \\
\hline Trauma $(<2 \%)$ & 92 & 120 & 277 & & \\
\hline $\begin{array}{l}\text { Total rejected \% } \\
(>0.5 \%)\end{array}$ & 47 (30.9\%) & 84 (37.7\%) & $110(22.8 \%)$ & 17.34 & 0.00017 \\
\hline $\begin{array}{l}\text { Total rejected \% } \\
(<0.5 \%)\end{array}$ & 105 & 139 & 372 & & \\
\hline FPD score over 40 & $13(8.6 \%)$ & $8(3.6 \%)$ & $9(1.9 \%)$ & 15.29 & 0.00047 \\
\hline FPD score under 40 & 139 & 215 & 473 & & \\
\hline
\end{tabular}

Table 2 summarizes the results of other welfare indicators evaluated by using the chi-square test. Comparison of large, medium and small flocks show a significant difference in the percentage of mortality, dead animals on arrival (DOA \%), average weigh at slaughter, stocking density (more than $\left.39 \mathrm{~kg} / \mathrm{m}^{2}\right), \%$ of total rejection of carcase, and FPD score (over 40).

Comparison of Campylobacter-positive samples in large, medium and small flocks did not show a significant difference $(p=0.159)$, although the highest prevalence of Campylobacter-positive cases was found in big flocks (6\%).

On the big farms, density decrease is practiced several times during one turn which could result in stress related to handling and to a new environment, which subsequently also causes a higher excretion of Campylobacter spp. into the environment.

It is interesting that in small flocks a significantly higher occurrence was found of FPD score over $40(\mathrm{p}=0.00047)$, stocking density exceeding $39 \mathrm{~kg} / \mathrm{m}^{2}(\mathrm{p}<0.00001)$, average slaughter weight higher than $1,800 \mathrm{~g}(\mathrm{p}<0.00001)$, as well as higher percentage of mortality over $2 \%$ (in 46.1, $\mathrm{p}=0.0085$ ).

In big flocks was detected significantly lowest FPD score over 40 (in 1.9\%), the percentage of total rejection of animals $(22.8 \%, \mathrm{p}=0.00017)$, lowest the stocking density (over $\left.39 \mathrm{~kg} / \mathrm{m}^{2}\right)$ of broiler flocks (in 2.3\%), and also the average slaughter weight $(>1.8 \mathrm{~kg})$. In each of the investigated big flocks, the average slaughter weight had not exceeded $2000 \mathrm{~g}$, what contributes to the low FPD score in broiler chickens in Iceland.

Significant highest prevalence of total rejection of animals and the percentage of mortality and trauma (over alarm level $2 \%)$ was detected in medium broiler flocks.

In two evaluated welfare indicators (\% of trauma over $2 \%$ and of the cleanliness of the inspected bodies - over level 1) was not proved a significant difference in small, medium, and big flocks.

\section{DISCUSSION}

In Iceland have been adopted laws and measures to control and prevent colonization of Campylobacter spp. in poultry flocks, which has significantly helped to reduce consumer exposure to Campylobacter spp. [23].

Biosecurity measures have been successfully introduced on poultry farms in Iceland in order to control the transmission of microorganisms from the environment to the flocks of broiler chickens. The common effort of the public health authorities and the poultry industry units, and the willingness of the latter to improve hygiene in housings, increase biosecurity measures, stress, cleaning and disinfection of crates in order to decrease cross-contamination, and to freeze the positive batches of carcasses, proved to be effective tools for the control of campylobacteriosis [14].

The number of Campylobacter-positive cases in the broiler flocks investigated between 2001-2018 in Iceland decreased 10 -fold. By comparison of temperature during the rearing with Campylobacter-positive cases (2016-2018) in boiler farms, seasonal variations of campylobacteriosis were found. In the period May - September, when the mean temperatures varied between $5-13^{\circ} \mathrm{C}$, the prevalence of Campylobacterpositive samples reached $90 \%$; however, during the colder season (December-March), smarkedly lower prevalence was detected (13\%). 
A lower prevalence of campylobacteriosis in the colder season (December - February) was also recorded in chicken flocks in the Czech Republic [24]. In a study from Scandinavian countries, a seasonal peak was found during the summer. In most European countries, the peak of campylobacteriosis occurred at the beginning of the year. The highest prevalence of Campylobacter spp. cases were seen in Slovakia, Hungary, the United Kingdom and Ireland in June. The cases of campylobacteriosis were less positively associated with temperature and precipitation [25].

The welfare of animals during rearing also affects the prevalence of infectious diseases. Poor environmental conditions may result in stress and susceptibility of the chickens to disease agents. Deterioration of welfare and rapid growth result in digestive problems and, subsequently, damp bedding which besides other factors, causes footpad dermatitis. Also the horizontal transmission of Campylobacter spp. is affected due to normal coprophagous activity of birds. In poultry flocks with high FPD (25-50\%) essed higher than $25 \%$ prevalence of Campylobacter spp was assessed. On the other hand, flocks with a lower than $13 \%$ prevalence of FPD were Campylobacter-negative [26].

The results obtained in the current study did not show a significant increase in the FPD score in Campylobacterpositive flocks $(p=0.65)$. Although there were no significant differences in mortality (> 2\%) between Campylobacterpositive and Campylobacter-negative flocks, mortality exceeded $2 \%$ and was very high: over $53.7 \%$ of Campylobacterpositive flocks and over $40.3 \%$ of Campylobacter-negative flocks,)which is undesirable from the economy point of view, and in particul indicates some deficiencies in the rearing of broiler chickens that may be associated with excessive stocking density, insufficient hygiene and sanitation, and the biological safety of poultry flocks.

The percentage of DOA found in the slaughterhouses due to infectious or non-infectious causes was significantly higher $(\mathrm{p}<0.00001)$ in big flocks, but significant difference was found between Campylobacter-positive and Campylobacternegative flocks $(\mathrm{p}=0.052)$.

DOA is positively associated with welfare indicators, including indicators of thermal stress, mortality on-farm during production (including selective culling), and effect of the transport of broilers over long distances. Significantly higher DOA\% $(\mathrm{p}=0.011)$ was found when farmers did not check chick quality upon arrival [27].

In Iceland, the low mean slaughter weight of broilers (up to $2000 \mathrm{~g}$ ) and the 35-day rearing cycle are important parameters for indicating improvement in welfare. The examination of welfare parameters in slaughterhouses in Iceland and the EU provides a direct but delayed picture about welfare and rearing conditions on farms. The disadvantage is that the information obtained in slaughterhouses cannot affect the relevant birds on farms and can result only in changes in the subsequent production cycles.Official veterinarians have only limited tools and opportunities to improve the welfare of commercial broiler flocks.

According to findings of the FPD score, the stocking density on the farms could be reduce. Two consecutive cases of score $41-80$ are lowering the density of $2 \mathrm{~kg} / \mathrm{m}^{2}$. One case of score above 80 is lowering the density of $3 \mathrm{~kg} / \mathrm{m}^{2}$ [16].

Associations between stocking density and the occurrence of footpad dermatitis were confirmed in small broiler flocks where a significant higher stocking density was observed $(\mathrm{p}<0.05)$ (over $1,800 \mathrm{~g}$ ), and also a significant higher FPD score over $40(\mathrm{p}<0.05)$. Similarly, a higher incidence of FPD in broilers was detected at higher stocking density, concerned with increased litter moisture, higher production of excrements, and poor heat transfer from the litter [28]. Some studies from UK revealed a surprisingly low effect of density of stocking on the health and living conditions of broiler chickens reared on commercial farms $[29,30]$.

In addition to stocking density, FPD can be related to the quality of management (insufficient control of moisture content of bedding). Damp bedding may be a consequence of the design of drinkers, high density, feeding, ventilation and health of the poultry. Insufficient control of moisture can cause lesions of the breast muscles and foot pads, and the occurrence of pododermatitis. These lesions may be painful and also may act as a portal for the entry of bacterial infectious agents [1].

The percentage of trauma in slaughtered animals from all flocks throughout the 3 years of study varied between $1.8 \%$ $-3.36 \%$, while the alarming level was $2 \%$. There was a high prevalence of injury and was routinely found in slaughtered broilers.

It was discovered that the manual catching and tilting system with a self-made conveyor belt system were the most criticised. The percentage of trauma could be also affected by transportation distance, stocking density and welfare during rearing, way of shackling, and overall stress during the manipulation of the poultry [13].

\section{CONCLUSIONS}

The prevalence of Campylobacter-positive and Salmonellapositive broiler flocks has been effectively reduced in Iceland in recent years.

Although in the current study no significant difference was observed in welfare parameters between Campylobacterpositive and Campylobacter-negative broiler flocks, in small, medium and big flocks there were significant differences in welfare and health parameters.

Most likely due to the highest stocking density of more than $39 \mathrm{~kg} / \mathrm{m}^{2}$, an average slaughter weight of more than $1,800 \mathrm{~g}$ was found in small the lowest stocking density and average slaughter weight, which significantly affected the lowest mortality rate, total rejection and FPD score in broilers. This results highlights the importance of stocking density interactions with footpad dermatitis and mortality in broiler flocks.

Reduction of the prevalence of Campylobacter spp. in poultry production requires strict application of prevention, biosecurity measures, control of microclimate parameters in poultry halls and also improvement and control of welfare of broiler flocks.

\section{REFERENCES}

1. RSPCA (2017). RSPCA welfare standards for chickens. https://www berspcaassured.org.uk/media/1236/rspca-welfare-standards-for-meatchickens.pdf (access: 2019.12.1).

2. EFSA 2010, Scientific Opinion on the influence of genetic parameters on the welfare and the resistance to stress of commercial broilers. EFSA Journal, 2010; 8: 7.

3. Gottstein B, Pozio E, Nöckler K. Epidemiology, diagnosis, treatment and control of trichinellosis. Clin Microbiol Rev. 2009; 22(1): 127-145. 
4. EFSA SCIENTIFIC REPORT The European Union summary report on trends and sources of zoonoses, zoonotic agents and foodborne outbreaks in 2016. EFSA J. 2017; 15(12): 5077, doi: 10.2903/j. efsa.2017.5077

5. Murphy D, Jolly C, MacDonald S, Troughton R. Myocarditis associated with Campylobacter jejuni. N Z Med J. 2013; 126(1375): 95-98.

6. Sibanda N, Mckenna A, Richmond A, Ricke SC, Callaway T, Stratakos $\mathrm{ACH}$, et al. A Review of the Effect of Management Practices on Campylobacter Prevalence in Poultry Farms. Front Microbiol. 2018. https://doi.org/10.3389/fmicb.2018.02002 (access: 2019.12.1).

7. Bull SA, Allen VM, Domingue G, Jørgensen F, Frost JA, Ure R, et al. Sources of Campylobacter spp. colonizing housed broiler flocks during rearing. Appl Anim Behav Sci. 2006; 72(1): 645-652.

8. Stern NJ, Meinersmann RJ, Cox NA, Bailey JS, Blankenship LC. Influence of host lineage on caecal colonization by Campylobacter jejuni in chickens. Avian Dis. 1990; 34(3): 602-606.

9. Newell DG, Fearnley C. Sources of Campylobacter colonization in broiler chickens. Appl Environ Microbiol. 2003; 69(8): 4343-4351.

10. Ridley AM, Morris VK, Cawthraw SA, Iversen JE, Harris JA, Kennedy EM, et al. Longitudinal molecular epidemiological study of thermophilic campylobacters on one conventional broiler chicken farm. Appl Environ Microbiol. 2011; 77(1): 98-107.

11. Messens W, Herman L, De Zutter L, Heyndrickx M. Multiple typing for the epidemiological study of contamination of broilers with thermotolerant Campylobacter. Vet Microbiol. 2009; 138(1-2): 120-131.

12. McDowell SW, Menzies FD, McBride SH, Oza AN, McKenna JP, Gordon AW, et al. Campylobacter spp. in conventional broiler flocks in Northern Ireland: epidemiology and risk factors. Prev Vet Med. 2008; 15(84): 261-276.

13. Stern NJ, Reiersen J, Lowman R, Bisaillon JR, Fridriksdottir V, Gunnarsson E, et al. Occurrence of Campylobacter spp. in cecal contents among commercial broilers in Iceland. Foodborne Pathog Dis. $2005 ; 2$ (1): $82-89$.

14. Humphrey T. Are happy chickens safer chickens? Poultry welfare and disease susceptibility. Br Poult Sci. 2006; 47(4): 379-391.

15. Barrios PR, Reiersen J, Lowman R, Bisaillon JR, Michel P, Fridriksdóttir $\mathrm{V}$, et al. Risk factors for Campylobacter spp. colonization in broiler flocks in Iceland. Prev Vet Med. 2006; 74(4): 264-278.

16. de Jong IC, van Harn J, Gunnink H, Hindle VA, Lourens A. Footpad dermatitis in Dutch broiler flocks: Prevalence and factors of influence. Poult Sci. 2012; 91(9): 1569-1574.

17. Welfare Quality 2009. The Welfare Quality ${ }^{\oplus}$ assessment protocol for poultry (broilers, laying hens). The Welfare Quality ${ }^{\circledR}$ Consortium, Lelystad, The Netherlands.
18. EN ISO 10272-1:2006 Microbiology of food and animal feeding stuffs - Horizontal method for detection and enumeration of Campylobacter spp. - Part 1: Detection method.

19. EN ISO 10272-1:2017 Microbiology of food and animal feed - Horizontal method for detection and determination of the counts of Campylobacter spp. - Part 1: Method of detection.

20. EN ISO 10272-2:2006 Microbiology of food and animal feeding stuffs - Horizontal method for detection and enumeration of Campylobacter spp. - Part 2: Colony-count technique.

21. EN ISO 10272-2:2017 Microbiology of the food chain - Horizontal method for detection and enumeration of Campylobacter spp. - Part 2: Colony-count technique.

22. NMKL 119, (NORDVAL INTERNATIONAL), 3. eddition, 2007, Thermotolerant Campylobacter. Detection, semi-quantitative and quantitative determination in foods and drinking water.

23. Stern NJ, Hiett KL, Alfredsson GA, Kristinsson KG, Reiersen J, Hardardottir $\mathrm{H}$, et al. Campylobacter spp. in Icelandic poultry operations and human disease. Epidemiol Infect. 2003; 130(1): 23-32.

24. Bořilová G, Svobodová I, Steinhauserová I, Gallas L. Occurrence of selected intestinal pathogens in slaughter chickens (In Czech). In Veterinářství. 2008; 58: 721-725.

25. Lake IR, Colón-González FJ, Takkinen J, Rossi M, Sudre B, Gomes Dias J, et al. Exploring Campylobacter seasonality across Europe using The European Surveillance System (TESSy), 2008 to 2016 Euro Surveill. 2019; 24(13): 1800028. doi: 10.2807/1560-7917.ES.2019.24.13.180028

26. Alpigiani I, Abrahantes JC, Michel V, Huneau-Salaün A, Chemaly M, Keeling LJ, et al. Associations between animal welfare indicators and Campylobacter spp. in broiler chickens under commercial settings: A case study. Prev Vet Med. 2017; 1(147): 186-193.

27. Jacobs L, Delezie E, Duchateau L, Goethals K, Tuyttens FA. Broiler chickens dead on arrival: associated risk factors and welfare indicators. Poult Sci. 2017; 96(2): 259-265.

28. Farhadi D, Hosseini SM, Dezfuli BT. Effect of house type on growth performance, litter quality and incidence of foot lesions in broiler chickens reared in varying stocking density. J Biosci Bioeng. 2016; 5(1): 69-78.

29. Dawkins MS, Donnelly CA, Jones TA. Chicken welfare is influenced more by housing conditions than by stocking density. Nature. 2004; 427: $342-344$.

30. Jones TA, Donnelly CA, Dawkins MS. Environmental and management factors affecting the welfare of chickens on commercial farms in the United Kingdom and Denmark stocked at five densities. Poult Sci. 2005; 84: 1155-1165. 